Rev. Elet. em Gestão, Educação e Tecnologia Ambiental (e-ISSN: 2236-1170)

\title{
GESTÃO DE RESÍDUOS SÓLIDOS URBANOS NO BRASIL: O CASO DE CANOAS, RS
}

\author{
Marcos Vinicius Godecke', lara Regina Chaves', Roberto Harb Naime \\ 'MSc.. Professor na UNIVATES-RS. Doutorando em Qualidade Ambiental na FEEVALE-RS. ERS-239, 2755, 93352-000 - Novo \\ Hamburgo (RS). mgodecke@yahoo.com.br \\ ${ }^{2}$ Mestre em Economia do Desenvolvimento na PUC-RS. Av. Ipiranga, 6681, Prédio 50, Sala 1105 \\ 90619-900 - Porto Alegre (RS). iara.chaves@ig.com.br \\ ${ }^{3}$ Dr. Professor no PPGQA/FEEVALE-RS. ERS-239, 2755, 93352-000 - Novo Hamburgo (RS). \\ rnaime@feevale.br
}

\section{RESUMO}

Este artigo buscou uma reflexão sobre a situação atual da gestão de resíduos sólidos urbanos no Brasil a partir do estudo do caso de Canoas, município situado na região metropolitana de Porto Alegre, estado do Rio Grande do Sul. Através de pesquisa bibliográfica, documental e entrevistas, foi encontrada uma situação ilustrativa das dificuldades vivenciadas pelos municípios gaúchos, que vão desde o descaso da população para o descarte e separação de recicláveis, até entraves econômicos, políticos e legais que obstacularizam as gestões municipais para a implementação de soluções sustentáveis sob o ponto de vista econômico, social e ambiental. Se, por um lado, a situação verificada em Canoas traduz as dificuldades dos municípios para práticas adequadas de gestão dos resíduos, por outro, mostra iniciativas como o fortalecimento das cooperativas de recicladores, que permitem antever a evolução nas práticas do setor na direção das premissas exigidas pela Política Nacional de Resíduos Sólidos, a Lei 12.305/2010.

Palavras-chave: gestão de resíduos sólidos urbanos, reciclagem, Canoas.

\begin{abstract}
This article presents a reflection on the current situation of solid waste management in Brazil from the case study of Canoas, a city located in the metropolitan region of Porto Alegre. Through research literature, documentary and interviews, the found situation illustrates the difficulties experienced by municipalities, ranging from the lack of public education for disposal and separation of recyclables, and economic, political and legal barriers for sustainable solutions for municipal waste management from economics, social and environmental points of view. If, on the one hand, the situation in Canoas reflects the difficulties of municipalities to practice proper waste management, the other, shows initiatives such the strengthening of recycling cooperatives, which allow us to predict evolutions in direction of 12,305 law premises.
\end{abstract}

Keywords: municipal waste management, municipal solid waste, recycling, Canoas. 
Rev. Elet. em Gestão, Educação e Tecnologia Ambiental (e-ISSN: 2236-1170)

\section{INTRODUÇÃO}

A excessiva geração de resíduos sólidos urbanos (RSU), combinada com a sua destinação inadequada, vêm contribuindo em larga escala para a depleção do meio ambiente, resultando na redução da capacidade de prestação dos serviços ecossistêmicos, essenciais à vida no Planeta.

A magnitude do impacto ambiental pelo descarte de resíduos pode ser depreendida a partir da estimativa da sua parcela coletada a nível mundial, estimada entre 2,5 e 4 bilhões de toneladas para o ano de 2004 (ABRELPE, 2007). No Brasil, a geração de resíduos sólidos urbanos (RSU) alcançou aproximadamente 61 milhões de toneladas no ano de 2010 - em torno de 1 kg por brasileiro ao dia da qual cerca de 30 milhões foram descartados diretamente no meio ambiente ou tiveram destinação inadequada, pela disposição em aterros precários ou vazadouros a céu aberto. No estado do Rio Grande do Sul (RS) aproximadamente 30\% dos RSU coletados ainda apresentam destinações inadequadas (ABRELPE, 2010)

Além do dano ambiental pela poluição do solo, ar e águas, superficiais e subterrâneas, o descarte inadequado dos RSU resulta em doenças, transmitidas por micro e macrovetores; em desconforto e desvalorização dos imóveis próximos aos locais de disposição final, pelos odores resultantes da decomposição dos resíduos orgânicos; e na aceleração do aquecimento global, pela emissão de gases de efeito estufa quando da decomposição da fração orgânica dos resíduos.

Essa situação remete à reflexão sobre a situação da gestão de resíduos urbanos no RS, vista neste artigo a partir do estudo de caso do município gaúcho de Canoas, situado na região metropolitana de Porto Alegre. Para tanto foram utilizadas num primeiro estágio pesquisas bibliográficas e documentais e, num segundo momento, entrevistas com atores envolvidos diretamente na atividade. De dezembro de 2010 a fevereiro de 2011 foram entrevistados servidores da Secretaria de Serviços Urbanos e Secretaria de Meio Ambiente da Prefeitura Municipal de Canoas, gestores da Cooarlas, uma das quatro cooperativas que executam a coleta seletiva municipal, além de instituições envolvidas em projeto de desenvolvimento das cooperativas de recicladores daquele município, capitaneado pelo programa de desenvolvimento sustentável (DRS) do Banco do Brasil.

Com o objetivo de conhecer as práticas locais de gestão relativas aos RSU, a escolha de Canoas para o desenvolvimento da pesquisa decorreu do interesse em avaliar os resultados de mudança para uma situação pouco comum em municípios de maior porte: a concessão do serviço de coleta seletiva diretamente às cooperativas de recicladores. Usualmente as prefeituras contratam empresas especializadas para o serviço, mediante licitação.

Além desta introdução e considerações finais, o artigo é composto por dois tópicos: o primeiro contextualiza a gestão de resíduos urbanos brasileira; o segundo dedica-se a posicionar o estado do RS no cenário nacional e aprofunda a análise a partir do caso de Canoas, município que compõe a área metropolitana de Porto Alegre, fazendo divisa com a capital.

\section{CONTEXTUALIZANDO A GESTÃO DE RESÍDUOS SÓLIDOS URBANOS NO BRASIL}




\section{Rev. Elet. em Gestão, Educação e Tecnologia Ambiental (e-ISSN: 2236-1170)}

A geração de RSU apresentou aceleração a partir do advento da revolução industrial - segunda metade do século XIX - por fatores ligados ao crescimento e migrações das populações, e aos modelos econômicos socialistas e capitalistas, predominantemente adotados.

A população mundial saltou de cerca de 1,6 bilhões de habitantes em 1900 para sete bilhões no ano de 2011, mais do que quadruplicando em cem anos. E concentrou-se em áreas urbanas, a exemplo da América Latina, que alcançou 76,5\% da população total vivendo nas cidades em 2005, num crescimento de $60 \%$ em apenas vinte anos (AIDIS, 2006).

O modelo capitalista de crescimento, pelo foco na acumulação de lucros, historicamente desprezou os danos sociais e ambientais decorrentes da atividade capitalista, nisso incluindo a despreocupação como o descarte inadequado dos resíduos, pela crença de que o progresso técnico e o capital físico, impulsionados pelas forças de mercado, substituíam integralmente o capital natural (ROMEIRO, 2010). O modelo capitalista é impulsionado mediante pesados investimentos em marketing visando o estímulo ao consumismo, numa dinâmica geradora de crescentes descartes que desafia a capacidade de carga do planeta (SANSON, 2005).

Além dos aspectos relativos ao crescimento populacional e aos modelos econômicos, também as novas tecnologias e formas de produção levaram as economias a novos patamares de produção, incrementando sobremaneira a geração de resíduos.

Procurando acompanhar essa evolução, principalmente nos países desenvolvidos, também a gestão dos resíduos urbanos tem evoluído na busca de uma visão sistêmica e integrada dessa atividade econômica, a gestão integrada de resíduos sólidos urbanos (GIRS). Nela, a atividade econômica é vista sob a ótica de um sistema aberto, no qual os diferentes atores - sociedade, governos, organizações não governamentais, etc - interagem nas etapas da gestão, compreendidas pela minimização, reuso, coleta e transporte, reciclagem, compostagem, recuperação energética e destinação final, sob diversos aspectos: técnicos, ambientais, econômicos, sociais, culturais, estratégicos, políticos e legais. Essa interação é percebida pelo seu aspecto dinâmico, variável ao longo do tempo, em diversas escalas, que vão da individual à global. Nessa abordagem é percebida a inter-relação do sistema de RSU com os demais sistemas urbanos, como o de esgotos, pluvial, paisagístico (KLUNDERT; ANSCHIITZ, 2000).

O planejamento da GIRS é estruturado sobre uma hierarquia, que foi inicialmente chamada de " $3 R$ " - redução, reuso e reciclagem - mas que teve a incorporação de um quarto " $R$ ", da recuperação ou valoração energética. Esta hierarquização está presente no corpo de legislações, como a brasileira, que na lei 12.305/2010 estabelece a seguinte priorização: não geração, redução, reutilização, reciclagem, recuperação energética e disposição final (BRASIL, 2010).

Os quatro " $R$ " estão presentes na Agenda 21, documento referenciado internacionalmente na conferência Rio92, pela proposição de quatro áreas de programas: (i) redução na geração; (ii) aumento da reutilização e reciclagem ambientalmente saudáveis; (iii) promoção do tratamento e depósito ambientalmente saudáveis; e (iv) a ampliação do alcance dos serviços que se ocupam dos resíduos (ONU, 1992).

Enquanto alguns países conseguem praticar de forma plena a hierarquização planejada, a exemplo da Holanda, que direciona $88 \%$ dos seus RSU para a reciclagem, compostagem e recuperação energética, resultando em apenas $12 \%$ a fração aterrada, outros direcionam para o aterramento a quase totalidade dos resíduos coletados, a exemplo do Brasil, que aproveita apenas cerca de $8 \%$ dos RSU via reciclagem e $2 \%$ pela compostagem (EPE, 2008). Segundo CEMPRE (2010), 


\section{Rev. Elet. em Gestão, Educação e Tecnologia Ambiental （e-ISSN: 2236-1170)}

apenas $8 \%$ dos municípios brasileiros operacionalizam algum tipo de coleta seletiva, numa abrangência que atinge apenas $12 \%$ da população brasileira.

Além da redução dos danos ao ambiente, saúde e clima, o estímulo ao reuso e reciclagem dos resíduos permite economias de energia, ao substituírem necessidades de novas produções, mais dispendiosas sob o ponto de vista energético, e ainda reduzem a pressão exploratória sobre as reservas naturais das matérias-primas utilizadas na produção. Também a compostagem, ao substituir a demanda por fertilizantes industriais, evita a extração dos nutrientes utilizados na sua fabricação.

Com a redução nas necessidades de produção via reuso, reciclagem e compostagem obtemos a diminuição da poluição associada aos processos de fabricação, resultando em aumento na vida útil dos aterros, pela redução na quantidade e volume de resíduos aterrados, na geração de emprego e renda, justamente para a camada mais necessitada da população (NAIME, 2005).

Segundo IPEA (2010), caso todos os recicláveis fossem aproveitados, os benefícios de ordem econômica e ambiental para o Brasil atingiriam R\$ 8 bilhões ao ano, em valores de 2007.

A precariedade da GRU brasileira resulta da conjunção de fatores de ordem cultural, política e institucional, entre outras. Aspectos culturais podem ser depreendidos da pesquisa Instituto Trata Brasil (2009), que constatou a baixa associação pela população entre as condições de saneamento básico e as doenças. Barreiras políticas e institucionais ficam aparentes quando tomamos a tramitação da "Política Nacional de Resíduos Sólidos" - lei 12305/2010 - que se estendeu por 19 anos, demonstrou a falta de priorização do tema para a classe política.

As fragilidades institucionais ficam aparentes pelo emperramento das licitações públicas através da via judicial, e na aplicabilidade do arcabouço legal, onde a divisão de funções no setor contribui para a falta de uma consciência regional que leve os municípios a buscar soluções conjuntas para seus problemas (PIRES et al., 2000).

Uma maior evolução da reciclagem e compostagem esbarram em aspectos financeiros, como o custo da coleta seletiva, cerca de quatro vezes maior que o da coleta tradicional - segundo CEMPRE (2010), o custo médio da coleta seletiva nas grandes cidades é estimado em US\$204,00, o valor médio da Coleta Regular de Lixo situa-se em US\$ 47,22 - e a baixa capacidade de geração de lucros pela comercialização dos compostados. Entre as dificuldades para a expansão da recuperação energética dos RSU estão a baixa penetração das tecnologias, decorre de fatores como a falta de uma política de viabilização no País e a falta de plantas piloto, que permitiriam tangibilizar a comparação entre as alternativas tecnológicas disponíveis. A recuperação energética via incineração encontra forte resistência pelo receio das consequências à saúde das emissões gasosas dessas usinas e por parte das associações de recicladores, que temem pela incineração de recicláveis (GODECKE, 2010).

A reversão desse quadro passa pela utilização de instrumentos de comunicação, visando à educação e conscientização da população; a utilização de instrumentos econômicos, como incentivos fiscais e proteções de mercado aos investimentos no setor; além da formulação de leis que ao tempo em que facilitem a adoção de soluções - como as leis 11.079/04, que regulamentou as parcerias público-privadas no âmbito da administração pública, e 11.107/05, que normatizou a contratação de consórcios públicos - forcem o investimento - como as leis $11.445 / 07$, que estabeleceu as diretrizes nacionais para o saneamento básico, e da já referida lei $12.305 / 10$, regulamentada pelo decreto 7.404, em 23 de dezembro de 2010 (BRASIL, 2004; 2005; 2007; 2010).

Inseridos nessa conjuntura macroeconômica, as regiões brasileiras apresentam variado grau de evolução na gestão de seus resíduos urbanos. No tocante à evolução do serviço de coleta de 
Rev. Elet. em Gestão, Educação e Tecnologia Ambiental (e-ISSN: 2236-1170)

recicláveis pelos municípios brasileiros, a Pesquisa Nacional de Saneamento Básico, realizada pelo Instituto Brasileiro de Geografia e Estatística (IBGE) no ano de 2008, levantou a existência de 994 municípios com alguma iniciativa de coleta seletiva no país. Segundo aquela pesquisa, o maior avanço ocorreu nas regiões Sul e Sudeste, onde 46,0\% e 32,4\% dos seus municípios, respectivamente, informaram a existência de programas de coleta seletiva (IBGE, 2010b).

Mais recente, a pesquisa ABRELPE (2010) levantou que, enquanto menos de $50 \%$ dos municípios das regiões Norte, Nordeste e Centro-oeste possuíam iniciativas de coleta seletiva em 2010, nas regiões Sul e Sudeste essa parcela estava na ordem de $80 \%$.

Este tópico buscou contextualizar a situação da gestão dos resíduos urbanos no Brasil. 0 próximo particulariza a análise para o caso do RS, aprofundando-a ao caso do município de Canoas.

\section{A GESTÃO DE RESÍDUOS SÓLIDOS URBANOS EM CANOAS (RS)}

De uma população pouco superior a um milhão de habitantes no início do século XX, em 2010 o RS possuía cerca de 10, 7 milhões de habitantes, com aproximadamente 9,1 milhões vivendo em áreas urbanas (IBGE, 2010b).

No tocante à gestão de resíduos, dos municípios do RS que participaram da pesquisa SNIS (2009), 92\% declararam ter coleta de resíduos e, destes, 41,92\% declararam oferecer serviço coleta seletiva. Quanto à destinação dos resíduos sólidos urbanos, dos 70 municípios gaúchos que responderam a referida pesquisa, 54,29\% tinham a disposição dos RSU em aterro sanitário, 31,43\% em aterro controlado e 14,29\% em lixões. Para o Brasil, dos 1006 municípios que responderam o questionário enviado pelo SNIS (2009), 35,39\% tinham a disposição dos RSU em aterro sanitário, $27,73 \%$ em aterro controlado e $36,88 \%$ em lixões (BRASIL, 2009).

Em análise dos benefícios potenciais da reciclagem sob aspectos de natureza econômica e ambiental, dimensionados para o RS com base nas informações de SNIS (2009), Chaves (2012) encontrou valores na ordem de $\mathrm{R} \$ 470$ mil ao ano.

A distância entre a otimização na GIRS experimentada por países desenvolvidos e a realidade vivenciada por um grande número de municípios brasileiros e gaúchos pode ser reduzida por iniciativas simples de gestão, como o apoio e capacitação das entidades associativas de recicladores. O caso do município gaúcho de Canoas, apresentado a seguir, permite aproximar essa discussão, até então colocada de forma genérica, à realidade vivenciada pelos municípios brasileiros de médio porte, onde a concentração populacional e industrial demandam maior ação dos agentes públicos e da sociedade em geral no trato com seus resíduos, sob a pena de verem potencializados os danos, principalmente ambientais e sociais, decorrentes de inadequações nessa gestão.

O município de Canoas abriga cerca de 320 mil habitantes, o segundo maior contingente populacional da região metropolitana de Porto Alegre, atrás apenas da própria Capital, concentrados numa área de apenas $131 \mathrm{~km}^{2}$, resultando em uma concentração demográfica da ordem de 2,5 mil pessoas por $\mathrm{km}^{2}$. A atividade econômica, com predomínio da industrial, resulta no segundo maior Produto Interno Bruto (PIB) do RS, da ordem de $\mathrm{R} \$ 12,6$ bilhões de reais em 2008, produzido pelo resultando num Produto Interno Bruto (PIB) per capita da ordem de R\$ 39 mil reais (IBGE, 2010a e 2012).

A pujança econômica do município se reflete numa proporcionalmente maior produção de 


\section{Rev. Elet. em Gestão, Educação e Tecnologia Ambiental （e-ISSN: 2236-1170)}

RSU, de 256 toneladas coletadas ao dia, equivalente a $0,79 \mathrm{~kg} / \mathrm{hab} / \mathrm{dia}$ (ABRELPE, 2010).

A destinação dos RSU do município tem variado ao longo do tempo. Até 1983 os resíduos coletados pelo município eram depositados em depressões, banhados e margens de rios, como no lado direito da rodovia BR 386, próximo da via férrea, a pedido dos proprietários dos lotes, que tinham interesse em atingir o nível da rodovia. A partir daquele ano o lixo passou a ser depositado a céu aberto, numa antiga jazida de argila na Fazenda Guajuviras. Após um grande incêndio, o Ministério Público estabeleceu prazo para que a Prefeitura remediasse a situação da área e implantasse um sistema com licenciamento ambiental. O local passou, então, a ser operado como aterro controlado. Em 1998 passou a operar como aterro sanitário, sem que a antiga área fosse recuperada - recebeu apenas uma cobertura de argila (PMC, [2006]).

A licença de operação do aterro da Fazenda Guajuviras encerrou em dezembro de 2010, sendo a solução atual o transporte dos RSU até o aterro da empresa SIL Soluções Ambientais Ltda, situado no município de Minas do Leão, distante cerca de $80 \mathrm{~km}$.

Em 1993 o município iniciou a coleta seletiva, num sistema porta a porta, para reciclagem na Associação de Carroceiros e Catadores de Material de Canoas. Em 2000, a empresa VEGA Engenharia passou a recolher o lixo seco. Em 2001 foram construídos três galpões de triagem, em convênio com a Fundação Estadual de Planejamento Metropolitano e Regional (METROPLAN), com gerenciamento pela Prefeitura Municipal. Além da coleta porta a porta, em 2006 funcionavam cerca de 200 postos de entrega voluntária (PEV) e as associações de reciclagem também realizavam coletas, de modo informal, resultando num volume coletado de 20 toneladas por mês - equivalente a cerca de $0,6 \%$ do total de resíduos coletados. A atividade abrangia $85 \%$ da população do município e empregava diretamente cerca de 90 trabalhadores, com ganhos médios na ordem de $\mathrm{R} \$ 400,00 / \mathrm{mês}$ (PMC, [2006]).

A gestão de resíduos urbanos de Canoas está dividida entre duas secretarias, a Secretaria de Serviços Urbanos, voltada para os serviços de coleta convencional, limpeza urbana, controle da destinação de resíduos de saúde, industriais e da construção civil; e a Secretaria de Meio Ambiente, que administra a coleta seletiva, promove a reciclagem, compostagem, ações de educação da população, e o relacionamento com as cooperativas de recicladores.

As cooperativas atuam na área urbana do município por concessão da Prefeitura, com áreas de atuação delimitadas por zoneamento na forma de quadrantes, divididos conforme o quadro 1.

Quadro 1. Associações de triagem conveniadas à Prefeitura Municipal de Canoas (RS)

\begin{tabular}{|c|c|}
\hline Quadrante Urbano & Associação \\
\hline Nordeste & ARLAS (Associação de Reciclagem de Lixo Amigas Solidárias) \\
\hline Sudeste & RENASCER (Associação de Reciclagem Renascer) \\
\hline Noroeste & ATEMAG (Associação de Triagem de Resíduos Mato Grande) \\
\hline Sudoeste & ACCMC (Associação de Carroceiros e Catadores de Materiais de Canoas) \\
\hline
\end{tabular}

Fonte. Elaboração dos autores

Em maio de 2010 as Cooperativas, que apenas processavam os recicláveis coletados, receberam a concessão do município para operacionalizar diretamente a coleta seletiva, com apoio financeiro da Prefeitura da ordem de $\mathrm{R} \$ 23$ mil ao mês e apoio técnico, através de cursos de capacitação estruturados pela Fundação La Salle, mediante convênio firmado com a Prefeitura Municipal de Canoas. 


\section{Rev. Elet. em Gestão, Educação e Tecnologia Ambiental （e-ISSN: 2236-1170)}

A mudança resultou no crescimento da coleta seletiva, de 6 para 13 toneladas diárias, num crescimento de $2,3 \%$ para $4,8 \%$ sobre o total de RSU coletados no município. A percepção dos entrevistados é de que há espaço para novos incrementos, via ampliação da área de atuação e aumento no número de coletas semanais: a coleta seletiva abrangia, em maio de $2010,86 \%$ da área urbana do município com uma coleta semanal. A atividade gerava emprego para 122 famílias, numa renda mensal que variava entre $\mathrm{R} \$ 500,00$ e $\mathrm{R} \$ 1.000,00$.

As cooperativas têm se articulado para a obtenção de ganhos de escala, como (i) a divisão no tempo de uso de uma máquina aglutinadora de plástico, que eleva o ganho por fardo de $R \$ 0,30$ a $R \$$ 3,00; (ii) na divisão da triagem dos RSU recebidos da coleta convencional, previsto para ocorrer na central de transbordo da Fazenda Guajuviras; (iii) e na busca de recursos do Banco Nacional de Desenvolvimento Econômico e Social (BNDES), em parceria com o programa Desenvolvimento Regional Sustentável (DRS) do Banco do Brasil S.A., para aquisição de caminhões de coleta, visando a atuação direta em substituição ao regime atual, de locação.

Vários programas municipais estão em implementação para a melhoria na gestão, como o Carroceiro Legal. Por esse programa as carroças são cadastradas e os carroceiros passam a receber cestas de alimentação, se cumprirem exigências ligadas à conduta ambiental, inclusive com a previsão de prestação de serviços comunitários, e outras como a obrigatoriedade de matrícula escolar dos filhos. Outro projeto, chamado Mais Educação, prevê palestras em escolas e indústrias sobre educação ambiental ligada aos resíduos. Em outra iniciativa, resíduos da construção civil são destinados à produção de vasos utilizados no ajardinamento de vias públicas. Por fim, o município se preparava para iniciar projeto de compostagem, pela separação de parte dos resíduos que transitam pela estação de transbordo da Fazenda Guajuviras.

Segundo os entrevistados, a parceria direta da Prefeitura com as cooperativas de recicladores, dentro de um processo planejado e controlado, tem resultado em vantagens mútuas: a Prefeitura gasta menos com o serviço de coleta seletiva e está obtendo uma maior eficiência em relação ao sistema anterior. A avaliação é de que a forma de remuneração que vigorava com a empresa que prestava o serviço de coleta seletiva, fixada sobre o roteiro, não envolvia o prestador de serviço nas quantidades coletadas. Ao contrário, maiores volumes implicavam no indesejado aumento no tempo de realização do "circuito de coleta".

A verticalização da operação, sob o ponto de vista das Cooperativas, representa a perspectiva de uma atuação profissional no mercado, com a perspectiva de significativa melhoria nas condições de emprego e renda. $O$ apoio financeiro e de capacitação promovido em parceria com a Prefeitura traz benefícios diretos como a proteção pela contratação de seguro de vida e acidentes pessoais ao grupo, incentivo à escolarização dos filhos dos cooperativados, capacitação desse pessoal como agentes ambientais, etc.. além da qualificação da gestão da cooperativa, pelo fornecimento de treinamentos na área de contabilidade, administração, cooperativismo, etc.

Observa-se que as ações implementadas pela Prefeitura, conjugadas a um longo histórico de parceria com as cooperativas de recicladores, iniciado em 1993, permitiu a formatação de uma solução de coleta seletiva que pode servir de inspiração para muitos gestores públicos municipais, pois satisfaz as principais dimensões da sustentabilidade: econômica, por gerar uma relação ganhaganha entre os parceiros; do ponto de vista social, traz capacitação e a perspectiva de redução da pobreza; e do ponto de vista ambiental, significa otimização no aproveitamento dos recicláveis. 
Rev. Elet. em Gestão, Educação e Tecnologia Ambiental (e-ISSN: 2236-1170)

\section{CONSIDERAÇÕES FINAIS}

Um olhar mais atento à problemática dos resíduos sólidos no Brasil e no Rio Grande do Sul mostra uma situação atual insatisfatória, haja vista a quantidade de municípios que ainda utilizam formas inadequadas de disposição final, o baixo aproveitamento de recicláveis e compostáveis, e a força dos aspectos econômicos, políticos e culturais que cerceiam essa evolução.

Por outro lado, percebe-se que segmentos da população tem clara percepção do problema, sendo crescente a preocupação das pessoas e empresas quanto à sustentabilidade, embora as ações efetivas para a reversão, tanto a nível pessoal como empresarial, sejam modestas. Se, de um lado, cresce nos indivíduos e empresas o conhecimento de "como" agir, de outro, há a leniência pela espera que outros tomem as iniciativas, pois as soluções no sentido da redução na geração dos resíduos passam por indesejáveis dispêndios financeiros, no caso das empresas, e mudanças nos hábitos de vida.

Em última análise, observa-se que as soluções estão contidas em três segmentos de ações: educacionais, atuando nos hábitos da população; econômicas, pela facilitação e incentivo às mudanças nas esferas individual, empresarial e pública; e aquelas ditas de "comando e controle", que forçam ao ajustamento às parcelas mais reticentes da sociedade.

Apesar do RS apresentar um retrato mais favorável de coleta seletiva, com maior número de municípios que fazem uso desse serviço em relação à média do país. Destinações inadequadas de disposição, apesar de em número reduzido, ainda estão presentes no estado, indicando a necessidade da atuação do poder público para o atendimento à lei $12.305 / 2010$, que determina o fim dos lixões até o ano de 2014.

Para a redução de custos da reciclagem e aumento da quantidade e qualidade dos recicláveis disponibilizados, podem ser utilizadas políticas como a disponibilização de postos de entrega voluntária, adoção de sistemas depósito-retorno juntamente com a oneração fiscal da atividade extratora das matérias primas-virgens, combinada com a desoneração fiscal da atividade da reciclagem e dos produtos resultantes da utilização de insumos reciclados.

Espera-se que o município, por força constitucional o responsável final pela correta destinação dos RSU, tome a frente do processo de evolução, como resposta ao desafio de transformar o "fardo" constitucional da prestação dos serviços relativos aos RSU, em desenvolvimento sustentável.

Neste contexto merecem destaque iniciativas como as implementadas no município objeto deste estudo, que ao tempo em que mostram-se simples e exequíveis, carregam forte componente de mudança na direção da GIRS. Dentre elas destacaram-se os resultados positivos obtidos pela concessão da operacionalização da coleta seletiva diretamente aos recicladores. Trata-se de modelo ainda pouco usual, mas que merece aprofundamento de estudo visando a ampliação da sua adoção pelos municípios brasileiros.

\section{REFERÊNCIAS}

AIDIS (ASOCIACIÓN INTERAMERICANA DE INGENIERÍA SANITARIA Y AMBIENTAL). Directrices para la Gestion 
Rev. Elet. em Gestão, Educação e Tecnologia Ambiental (e-ISSN: 2236-1170)

Integrada y Sostenible de Residuos Solidos Urbanos en America Latina y el Caribe. AIDIS y Centro Internacional de Investigaciones para el Desarrollo - IDRC. São Paulo: 2006, 118 p. Disponível em: <www.polis.org.br>. Acesso em: 22 nov. 2008.

ABRELPE (ASSOCIAÇÃO BRASILEIRA DE EMPRESAS DE LIMPEZA PÚBLICA E RESÍDUOS ESPECIAIS) . Panorama dos resíduos sólidos no Brasil 2007. Disponível em: <www.abrelpe.org.br>. Acesso em: 2 maio 2009.

. Panorama dos resíduos sólidos no Brasil 2010. Disponível em: <www.abrelpe.org.br>. Acesso em: 23 mar. 2012.

BRASIL. Decreto no 7.404, de 23 de dezembro de 2010. Regulamenta a Lei $n^{\circ}$ 12.305, de 2 de agosto de 2010, que institui a Política Nacional de Resíduos Sólidos, cria o Comitê Interministerial da Política Nacional de Resíduos Sólidos e o Comitê Orientador para a Implantação dos Sistemas de Logística Reversa, e dá outras providências.

. Lei no 11.079, de 30 de dezembro de 2004. Institui normas gerais para licitação e contratação de parceria público-privada no âmbito da administração pública.

Lei no 11.107, de 06 de abril de 2005. Dispõe sobre normas gerais de contratação de consórcios públicos e dá outras providências.

Lei no 11.445, de 05 de janeiro de 2007. Estabelece diretrizes nacionais para o saneamento básico e dá outras providências.

Lei no 12.305, de 2 de Agosto de 2010. Institui a Política Nacional de Resíduos Sólidos; altera a Lei $\underline{9605}$, de 12 de fevereiro de 1998; e dá outras providências.

. MINISTÉRIO DAS CIDADES. SNIS Serie Histórica 7. Brasilia: Secretaria Nacional de Informações sobre Saneamento/MCidades, $2009 . \quad$ Disponível em: <http://www.snis.gov.br/PaginaCarrega.php?EWRErterterTERTer=91>. Acesso em: 23 mar. 2011.

CHAVES, I. R.. Benefícios Sociais, Econômicos e Ambientais a partir da Gestão de Resíduos Sólidos Urbanos: Uma Estimação para o Rio Grande do Sul. Dissertação de Mestrado em Economia do Desenvolvimento na PUCRS. Porto Alegre, 2012, 60 p. e 90 p.

CEMPRE (COMPROMISSO EMPRESARIAL PARA RECICLAGEM). Pesquisa CICLOSOFT 2010. Disponível em: < www.cempre.org.br/ciclosoft_2010.php>. Acesso em: 13 fev. 2011. Homepage institucional.

EPE (EMPRESA DE PESQUISA ENERGÉTICA). Nota Técnica DEN 06/08: Avaliação Preliminar do Aproveitamento Energético dos Resíduos Sólidos Urbanos de

Campo Grande, MS. Ministério das Minas e Energia (MME)/Empresa de Pesquisa Energética (EPE). Rio de Janeiro, Nov. 2008.

GODECKE, M.V.. Estudo das Alternativas de Valorização Econômica para a Sustentabilidade da Gestão de Resíduos Urbanos no Brasil. Dissertação de Mestrado em Economia do Desenvolvimento na PUCRS. Porto Alegre, 2010, $185 \mathrm{p}$. 
Rev. Elet. em Gestão, Educação e Tecnologia Ambiental （e-ISSN: 2236-1170)

IBGE (INSTITUTO BRASILEIRO DE GEOGRAFIA E ESTATÍSTICA ). Cidades. Disponível em: <http://www.ibge.gov.br/cidadesat/link.php?codmun=430460>. Acesso em: 23 mar. 2012.

Dados do Censo 2010 publicados no Diário Oficial da União do dia 04/11/2010. Disponível em: <www.ibge.gov.br/censo2010/dados_divulgados/index.php?uf=43>. Acesso em: 13 fev. 2011 . Homepage institucional.a

. Pesquisa Nacional de Saneamento Básico 2008. Rio de Janeiro, 2010.b

IPEA (INSTITUTO DE PESQUISAS ECONÔMICAS APLICADAS). Relatório de Pesquisa: Pesquisa sobre Pagamento por Serviços Ambientais Urbanos para Gestão de Resíduos Sólidos. Diretoria de Estudos e Políticas Regionais, Urbanas e Ambientais (DIRUR). Brasília, 2010, 63p.

INSTITUTO TRATA BRASIL. Percepções sobre saneamento básico. Pesquisa IBOPE. 12 ago. 2009. Disponível em: <www.tratabrasil.org.br/novo_site/cms/APRESENTACAO_IBOPE_TRATA/Apresentacao_coletiva_12ago.pdf>.

Acesso em: 18 out. 2009.

KLUNDERT, A. V.; ANSCHIITZ, J.. The Sustainability of Alliances Between Stakeholders in Waste Management. Working paper for UWEP/CWG, 30 May 2000 - Draft. Disponível em: <www.gdrc.org/uem/waste/ISWM. pdf >. Acesso em: 13 mar. 2009.

NAIME, R.. Gestão de resíduos sólidos: uma abordagem prática. Novo Hamburgo: FEEVALE, 2004, 134 p.

ONU (ORGANIZAÇÃO DAS NAÇÕES UNIDAS). Conferência das Nações Unidas sobre o Meio Ambiente e o $\begin{array}{llllll}\text { Desenvolvimento } & \text { (CNUMAD). } & \text { Agenda } & 21 . & 1992 . & \text { Disponível }\end{array}$ <www.ecolnews.com.br/agenda21/index.htm>. Acesso em: 7 mar. 2009.

PIRES et al.. Plano Diretor de Resíduos Sólidos da Região Metropolitana de Porto Alegre. In: XXVII Congresso Interamericano de Engenharia Sanitária e Ambiental. 3 - 8 dez. 2000. Porto Alegre (RS). Anais eletrônicos... Porto Alegre.

PMC (PREFEITURA MUNICIPAL DE CANOAS). Resíduos Sólidos. Plano Diretor Urbano Ambiental-Canoas/RS. Secretaria Municipal do Planejamento Urbano. [2006]. Disponível em: <www.canoas.rs.gov.br/PDUA/ARQ57.pdf>. Acesso em: 13 fev. 2011.

ROMEIRO, A. R.. Economia ou Economia Política da Sustentabilidade. In: MAY, P. H. (org.). Economia do Meio Ambiente: Teoria e Prática. 2a ed. Rio de Janeiro: Elsevier, 2010. 379 p.

SANSON, J.R.. Ethics, Politics, and Nonsatiation in Consumption: A Synthesis. In: 33을 Encontro Nacional de Economia, 6 - 9 dez. 2005, Natal (RN). Anais eletrônicos... Natal. 